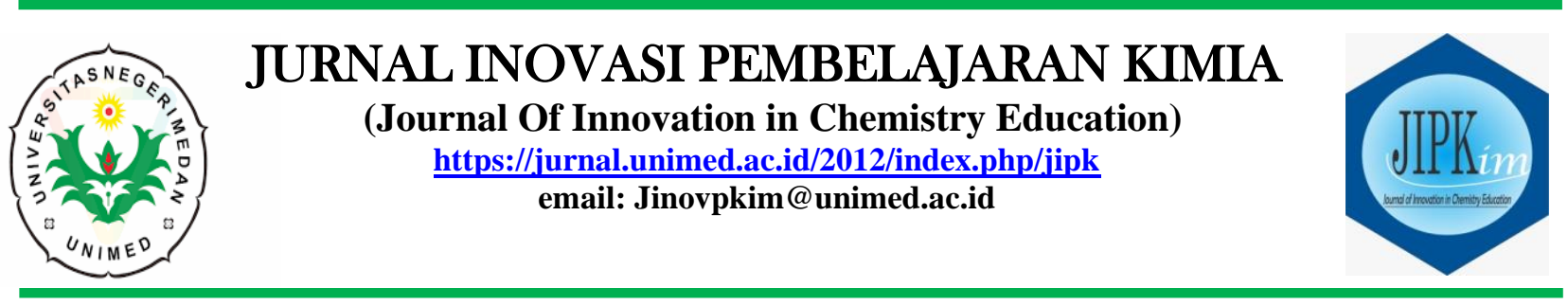

\title{
IMPLEMENTASI MODEL PEMBELAJARAN PROBLEM BASED LEARNING DENGAN PENDEKATAN SAINTIFIK TERHADAP HASIL BELAJAR LAJU REAKSI SISWA
}

\author{
Aisyatur Radhwa Marpaung ${ }^{\mathrm{a}, *}$, Ani Sutiani ${ }^{\mathrm{a}}$ \\ ${ }^{a}$ Program Studi Pendidikan Kimia, Universitas Negeri Medan, Medan \\ *Alamat Korespondensi: aisyal105syakirahafra@gmail.com
}

\begin{abstract}
:
One of the subject matter of Chemistry High School which has quite extensive studies and full of concepts is Reaction Rate. The subject matter will be more precisely taught through Problem Based Learning (PBL) with scientific approach that designed with surrounding environment. This study aims to determine difference between increasing learning outcomes learned through PBL with scientific approach and increasing learning outcomes learned through Direct Instruction (DI) with scientific approach on Reaction Rate. The population was all students of XI MIA MAN. The sampling technique in this study was purposive sampling. The results showed an increase in student learning outcomes in experimental class by $84 \%$ and in control class by $79 \%$. Based on test of the real difference with the statistical technique $t$ at the level of significance $\alpha=0.05$ on the results of this study it can be concluded that increase in student learning outcomes through the PBL with scientific approach is higher than increase in learning outcomes taught through the DI with scientific approach to Reaction rate.
\end{abstract}

Keywords:

Problem Based Learning, Direct Instruction, Scintific Approach, Learning Outcomes, Reaction Rate

\section{PENDAHULUAN}

Problem Based Leraning (PBL) merupakan metode instruksional yang menantang siswa agar "belajar untuk belajar", bekerja sama dalam kelompok untuk mencari solusi bagi permasalahan. PBL mempersiapkan siswa untuk berpikir kritis dan analitis, dan untuk mencari serta menggunakan sumber belajar yang sesuai sebagaimana dikutip oleh Amin (dalam Anggraini, 2013). Karakteristik model pembelajaran PBL adalah: 1) Permasalahan menjadi starting point dalam belajar, 2) Permasalahan menantang pengetahuan yang dimiliki oleh siswa, sikap, dan kompetensi yang kemudian membutuhkan identifikasi kebutuhan belajar dan bidang baru dalam belajar, 3) Pemanfaatan sumber pengetahuan yang beragam penggunaannya, dan evaluasi sumber informasi merupakan proses yang esensial dalam PBL, 4) Belajar adalah kolaboratif, komunikasi, dan kooperatif, 5) Pengembangan keterampilan inquiry dan pemecahan masalah sama pentingnya dengan penguasaan isi pengetahuan untuk mencari solusi dari sebuah permasalahan, dan 6) PBL melibatkan evaluasi dan reviewpengalaman siswa dan proses belajar (Rusman, 2011).

Machin (2014), mendapatkan bahwa pembelajaran melalui pendekatan saintifik adalah proses pembelajaran yang dirancang sedemikian rupa agar peserta didik secara aktif mengonstruksi konsep, hukum atau prinsip melalui tahapan-tahapan mengamati 
(untuk mengidentifikasi atau menemukan masalah), merumuskan masalah, mengajukan atau merumuskan hipotesis, mengumpulkan data dengan berbagai teknik, menganalisis data, menarik kesimpulan dan mengomunikasikan konsep, hukum atau prinsip yang ditemukan.

Sedangkan menurut Yerimadesi dkk., (2017) menyatakan bahwa pendekatan saintifik (scientific approach) merupakan salah satu pendekatan pembelajaran yang berorientasi atau berpusat pada siswa. Oleh karena itu, kondisi pembelajaran yang diharapkan tercipta diarahkan untuk mendorong peserta didik dalam mencari tahu dari berbagai sumber melalui observasi (Sani, 2014).

Pengajaran langsung adalah model pembelajaran yang berpusat pada guru,yang mempunyai 5 langkah dalam pelaksanaannya, yaitu menyiapkan siswa menerima pelajaran, demonstrasi, pelatihan terbimbing, umpan balik, dan pelatihan lanjut (mandiri).

Menurut Dimyati dan Mujiono (2002) "Hasil belajar merupakan hasil dari suatu interaksi tindak belajar dan tindak mengajar. Dari sisi guru, tindak mengajar diakhiri dengan proses evaluasi hasil belajar. Dari sisi siswa, hasil belajar merupakan berakhirnya pengalaman dan puncak proses belajar".

Bidang kimia yang mengkaji kecepatan atau laju terjadinya reaksi kimia dinamakan kinetika kimia. Kata "Kinetik" menyiaratkan gerakan atau perubahan. Energi kinetik didefinisikan sebagai energi yang tersedia karena gerakan suatu benda. Disini, kinetika merujuk pada laju reaksi, yaitu perubahan konsentrasi reaktan atau produk terhadap waktu (M/s).

Adapun tujuan penelitian ini adalah: Untuk mengetahui peningkatan hasil belajar siswa melalui penerapan model Problem Based Learning dengan pendekatan saintifik dan menggunakan model Direct Instruction dengan pendekatan saintifik.

\section{METODE}

Penelitian ini menggunakan teknik pengambilan sampel purposive sampling. Populasi penelitian adalah seluruh siswa kelas XI MIA MAN. Masing-masing kelas berjumlahkan 44 hingga 45 siswa. Penelitian ini melibatkan dua variabel bebas (model PBL dengan pendekatan saintifik dan model DI) dan satu variabel terikat (hasil belajar kimia siswa). Instrumen yang digunakan adalah tes hasil belajar pada materi pokok laju reaksi. Teknik analisis data yang digunakan adalah analisis dengan menggunakan rumus Uji-t yang terlebih dahulu dilakukan Uji Normalitas dan Uji Homogenitas Data.

\section{HASIL DAN PEMBAHASAN Deskripsi Data Hasil Belajar Kimia}

Data yang terdapat dalam penelitian ini diperoleh dari pretest yang diujikan sebelum dilakukan proses pembelajaran pada kedua kelompok sampel (kelas eksperimen dan kelas kontrol) dan posttest yang diujikan setelah dilakukan proses pembelajaran menggunakan model Problem Based Learning dengan pendekatan saintifik pada kelas eksperimen dan model pembelajaran Direct Instruction dengan pendekatan saintifik pada kelas kontrol. Kegunaan pretest adalah untuk melihat kehomogenan kedua kelompok sampel dan penentuan sampel. Perolehan nilai rata-rata pretest pada kelas eksperimen adalah 44,2, sedangkan nilai rata-rata pretest untuk kelas kontrol adalah 41,02. Kegunaan posttest adalah untuk melihat hasil belajar masing-masing sampel setelah diberi perlakuan. Perolehan nilai rata-rata posttest pada kelas eksperimen adalah 87,11, sedangkan nilai rata-rata posttest untuk kelas kontrol adalah 80,34.

\section{Analisis Data Hasil Penelitian}

Berdasarkan data nilai hasil belajar siswa yang diperoleh pada penelitian ini dan setelah data ditabulasikan maka diperoleh rata-rata, standar deviasi dan varians dari data pretest dan postest dari kelas eksperimen dan kelas kontrol seperti pada Tabel 1. 
Tabel 1. Rata-rata, Standar Deviasi,dan Varians Data Pretest dan Posttest

\begin{tabular}{|c|c|c|c|c|c|c|}
\hline \multirow{2}{*}{ Kelas } & \multicolumn{2}{|c|}{$\begin{array}{l}\text { Nilai Rata } \\
\text { - Rata }\end{array}$} & \multicolumn{2}{|c|}{$\begin{array}{l}\text { Standar } \\
\text { Deviasi }\end{array}$} & \multicolumn{2}{|c|}{ Varians } \\
\hline & $\begin{array}{l}\text { Pret } \\
\text { est }\end{array}$ & $\begin{array}{l}\text { Post } \\
\text { test }\end{array}$ & $\begin{array}{l}\text { Pret } \\
\text { est }\end{array}$ & $\begin{array}{l}\text { Post } \\
\text { est }\end{array}$ & $\begin{array}{l}\text { Pre } \\
\text { test }\end{array}$ & $\begin{array}{l}\text { Post } \\
\text { est }\end{array}$ \\
\hline $\begin{array}{l}\text { Eksperi } \\
\text { men }\end{array}$ & 44,2 & 87,1 & 11,4 & 3,91 & $\begin{array}{r}130 \\
, 63\end{array}$ & 15,3 \\
\hline Kontrol & 41,0 & 80,3 & 9,7 & 4,23 & $\begin{array}{l}94, \\
85\end{array}$ & 17,9 \\
\hline
\end{tabular}

\section{Data Peningkatan Hasil Belajar} (N-Gain)

Hasil perhitungan peningkatan hasil belajar dapat langsung dicari dari rata-rata nilai gain seluruh siswa untuk masing-masing kelas yaitu peningkatan hasil belajar untuk kelas eksperimen sebesar 0,84 atau $84 \%$ dan kelas kontrol sebesar 0,79 atau $79 \%$ seperti pada Tabel 2.

Tabel 2. Peningkatan Hasil Belajar

\begin{tabular}{ccccc}
\hline Kelas & Kriteria & $\Sigma \mathrm{X}$ & $\%$ & Ket \\
& & & $\mathrm{g}$ & \\
\hline Eksperi & $\mathrm{g}<0,3=$ & $\Sigma \mathrm{X}=$ & 84 & Tinggi \\
men & Rendah & 0,84 & $\%$ & \\
& $0,3<\mathrm{g}>0,7$ & & & \\
& $=$ Sedang & $\Sigma \mathrm{X}=$ & 79 & Tinggi \\
Kontrol & $\mathrm{g}>0,7=$ & 0,79 & $\%$ & \\
& Tinggi & & & \\
\hline
\end{tabular}

Dari data pada Tabel 2 dapat dilihat bahwa peningkatan hasil belajar pada kelas eksperimen dan kontrol termasuk kategori tinggi.

\section{Uji Normalitas}

Pengujian normalitas data dilakukan menggunakan uji Chi-Kuadrat, diperoleh bahwa nilai pretest dan posttest kedua kelompok sampel memiliki data yang normal atau $\left(X^{2}\right)_{\text {hitung }}<\left(X^{2}\right)_{\text {tabel }}$ pada taraf signifikan 0,05 untuk kelas eksperimen dan kelas kontrol maka dapat dinyatakan bahwa data terdistribusi normal seperti yang ditunjukkan pada Tabel 3.
Tabel 3. Uji Normalitas Data Pretest dan Posttest

\begin{tabular}{ccccc}
\hline No & Data & $X^{2}$ & $X^{2}$ & Kesimpulan \\
\hline 1 & $\begin{array}{c}\text { Pretest } \\
\text { Kelas } \\
\text { Eksperimen } \\
\text { Pretest }\end{array}$ & 10,972 & 11,07 & Normal \\
2 & $\begin{array}{l}\text { Kelas } \\
\text { Kontrol } \\
\text { Posttest } \\
\text { Kelas }\end{array}$ & 9,954 & 11,07 & Normal \\
3 & 10,757 & 11,07 & Normal \\
& $\begin{array}{c}\text { Eksperimen } \\
\text { Posttest } \\
\text { Kelas } \\
\text { Kontrol }\end{array}$ & 10,041 & 11,07 & Normal \\
\hline
\end{tabular}

Berdasarkan Tabel 3 disimpulkan bahwa:

1. Uji normalitas data pretest siswa kelas eksperimen diperoleh $\left(X^{2}\right)$ hitung untuk pretest 10,972 dengan mengambil taraf nyata $\alpha=0,05$ dan dk 5 adalah 11,07 dari data terlihat $\left(X^{2}\right)_{\text {hitung }}<\left(X^{2}\right)_{\text {tabel }}$ maka dapat disimpulkan data pretest siswa berdistribusi normal.

2. Uji normalitas pretest siswa kelas kontrol diperoleh $\left(X^{2}\right)$ hitung untuk pretest 9,954 dengan mengambil taraf nyata $\alpha=$ 0,05 dan dk 5 adalah 11,07 dari data terlihat $\left(X^{2}\right)_{\text {hitung }}<\left(X^{2}\right)_{\text {tabel }}$ maka dapat disimpulkan data pretest berdistribusi normal.

3. Uji normalitas data hasil belajar siswa kelas eksperimen diperoleh $\left(X^{2}\right)_{\text {hitung }}$ untuk posttest 10,757 dengan mengambil taraf nyata $\alpha=0,05$ dan $\mathrm{dk} 5$ adalah 11,07 dari data terlihat $\left(X^{2}\right)_{\text {hitung }}<\left(X^{2}\right)_{\text {tabel }}$ maka dapat disimpulkan data hasil belajar kimia siswa berdistribusi normal.

4. Uji normalitas data hasil belajar siswa kelas kontrol diperoleh $\left(X^{2}\right)_{\text {hitung untuk }}$ posttest 10,041 dengan mengambil taraf nyata $\alpha=0,05$ dan $\mathrm{dk} 5$ adalah 11,07 dari data terlihat $\left(X^{2}\right)_{\text {hitung }}<\left(X^{2}\right)_{\text {tabel }}$ maka dapat disimpulkan data hasil belajar kimia siswa berdistribusi normal. 


\section{Uji Homogenitas}

Hasil perhitungan uji homogenitas untuk data pretest dan posttest kedua kelas Eksperimen dan Kontrol dengan membandingkan $\mathrm{F}_{\text {hitung }}$ dan $\mathrm{F}_{\text {tabel }}$ dikatakan homogen apabila harga $\mathrm{F}_{\text {hitung }}<\mathrm{F}_{\text {tabel }}$ pada taraf signifikasi $\alpha=0,05$ dapat dilihat pada Tabel 4.

Tabel 4. Uji Homogenitas Sampel

\begin{tabular}{cccccc}
\hline $\begin{array}{c}\text { Sumber } \\
\text { Data }\end{array}$ & Kelas & $\mathrm{S}^{2}$ & $\begin{array}{c}\mathrm{F} \\
\text { hitung }\end{array}$ & $\mathrm{F}_{\text {tabel }}$ & Ket \\
\hline \multirow{4}{*}{ Pretest } & $\begin{array}{c}\text { Eksperi } \\
\text { men }\end{array}$ & $\begin{array}{c}130, \\
63\end{array}$ & & & \\
\cline { 2 - 3 } & Kontrol & $\begin{array}{c}94,8 \\
5\end{array}$ & 1,37 & 1,68 & $\begin{array}{c}\text { Homo } \\
\text { gen }\end{array}$ \\
& $\begin{array}{c}\text { Eksperi } \\
\text { men }\end{array}$ & $\begin{array}{c}15,3 \\
2\end{array}$ & & & \\
\cline { 2 - 3 } Posttest & 1,16 & 1,68 & $\begin{array}{c}\text { Homo } \\
\text { gen }\end{array}$ \\
& Kontrol & $\begin{array}{c}17,9 \\
0\end{array}$ & & & \\
\hline
\end{tabular}

Untuk nilai pretest dan posttest kelas eksperimen dan kelas kontrol berdasarkan tabel nilai untuk distribusi $\mathrm{F}$ dengan taraf nyata $\alpha=0,05$ dan $\mathrm{db}$ pembilang 44 serta $\mathrm{db}$ penyebut 43 sehingga $F_{\text {tabel }} F_{0,05}(44,43)=1,68$. Karena harga $F_{\text {hitung }}<F_{\text {tabel}}$, maka dapat disimpulkan bahwa data pretest dan posttest kedua kelas tersebut adalah homogen.

\section{Uji Hipotesis}

Hipotesis alternatif (Ha) untuk hipotesis I adalah peningkatan hasil belajar siswa yang dibelajarkan menggunakan model Problem Based Learning dengan pendekatan saintifik lebih tinggi daripada peningkatan hasil belajar ranah kognitif siswa yang dibelajarkan dengan menggunakan model Direct Instruction dengan pendekatan saintifik. Data hasil perhitungan uji hipotesis I dapat dilihat pada Tabel 5.

Tabel 5. Data Hasil Uji Hipotesis Peningkatan Hasil Belajar

\begin{tabular}{ccccc}
\hline \multicolumn{2}{c}{ Data Kelas } & t $\mathrm{t}_{\text {hitung }}$ & $\mathrm{t}_{\text {tabel }}$ & Ket \\
\cline { 1 - 2 } Eksperimen & Kontrol & & & \\
& $\bar{g}=0,79$ & & & Ha \\
$\overline{\boldsymbol{g}}=0,84$ & $\mathrm{~S}^{2}=$ & 2,244 & 1,662 & diterima, \\
$\mathrm{S}^{2}=0,0077$ & 0,0081 & & & Ho ditolak \\
& & & \\
\hline
\end{tabular}

Berdasarkan kriteria pengujian hipotesis yaitu tolak Ho jika thitung berada di daerah kritis. Dari perhitungan ini, diperoleh $t_{\text {hitung }}$ peningkatan hasil belajar sebesar 2,244 dan terletak di daerah kritis, sedangkan $t_{\text {tabel }}$ sebesar 1,662 sehingga $t_{\text {hitung }}>t_{\text {tabel }}$, maka Ha diterima dan Ho ditolak. Hal ini berarti peningkatan hasil belajar siswa yang mendapat pembelajaran model Problem Based Learning dengan pendekatan saintifik lebih tinggi pada peningkatan hasil belajar siswa yang mendapat pembelajaran yang menggunakan model Direct Instruction dengan pendekatan saintifik pada materi Laju Reaksi. Dari hasil penelitian diperoleh peningkatan hasil belajar (gain) siswa pada kelas eksperimen yaitu $84 \%$, sedangkan pada kelas kontrol yaitu 79\%. Hasil dari selisih peningkatan hasil belajar antara kedua kelas adalah sebesar $5 \%$.

\section{KESIMPULAN}

Setelah melakukan penelitian, perhitungan data serta pengujian hipotesis maka kesimpulan yang didapat adalah:

1. Hasil belajar siswa dengan penerapan model pembelajaran Problem Based Learning dengan pendekatan saintifik pada kelas eksperimen lebih tinggi dengan nilai rata-rata 87,11 sedangkan pada kelas kontrol yaitu 80,34. Nilai rata-rata hasil belajar pada kelas eksperimen sudah mencapai kriteria ketuntasan minial (KKM) pada MAN 1 Medan yaitu 80, namun pada kelas kontrol belum mencapai kriteria ketuntasan minial (KKM).

2. Model pembelajaran Problem Based Learning dengan pendekatan saintifik terdapat pengaruh yang signifikan. Hal ini dapat dilihat dari hasil perhitungan uji hipotesis melalui uji-t pada taraf signifikan $\alpha=0,05$ didapat hasil $\mathrm{t}_{\mathrm{hit}}>\mathrm{t}_{\mathrm{tab}}$ atau 2,244>1,662 data tersebut dapat disimpulkan bahwa $\mathrm{H}_{0}$ ditolak dan menerima $\mathrm{H}_{\mathrm{a}}$. 


\section{DAFTAR PUSTAKA}

Anggraini, V. D., \& Mukhadis, A. (2013). Problem based learning, motivasi belajar, kemampuan awal, dan hasil belajar siswa SMK. Jurnal Ilmu Pendidikan, 19(2):187-195.

Dimyati \& Mujiono., (2002). Belajar dan Pembelajaran. Jakarta. Rineka Cipta.

Machin, A. (2014). Implementasi pendekatan saintifik, penanaman karakter dan konservasi pada pembelajaran materi pertumbuhan. Jurnal Pendidikan IPA Indonesia, 3(1):28-35.

Rusman., (2011). Model-model Pembelajaran: Mengembangkan Profesionalisme Guru. Rajawali Pers/PT Raja Grafindo Persada.

Sani, R. A., (2014). Pembelajaran Saintifik Untuk Implementasi Kurikulum 2013, Jakarta. PT Bumi Aksara.

Silitonga, P. M., (2013). Statistika Teori Dan Aplikasi Dalam Penelitian. Universitas Negeri Medan. FMIPA.

Sugiyono, (2017). Metode Penelitian Pendidikan, Alfabeta, Bandung.

Yerimadesi, Y., Bayharti, B., Handayani, F., \& Legi, W. F., (2017). Pengembangan Modul Kesetimbangan Kimia Berbasis Pendekatan Saintifik Untuk Kelas XI SMA/MA. Sainstek: Jurnal Sains dan Teknologi, 8(1):85-97. 